Open Scientist Handbook • OSH

\title{
Is My Learned Society Obsolete?
}

\author{
Bruce R. Caron
}

Published on: Mar 10, 2021

DOI: 10.21428/8bbb7f85.f3059b40

License: Creative Commons Attribution 4.0 International License (CC-BY 4.0). 


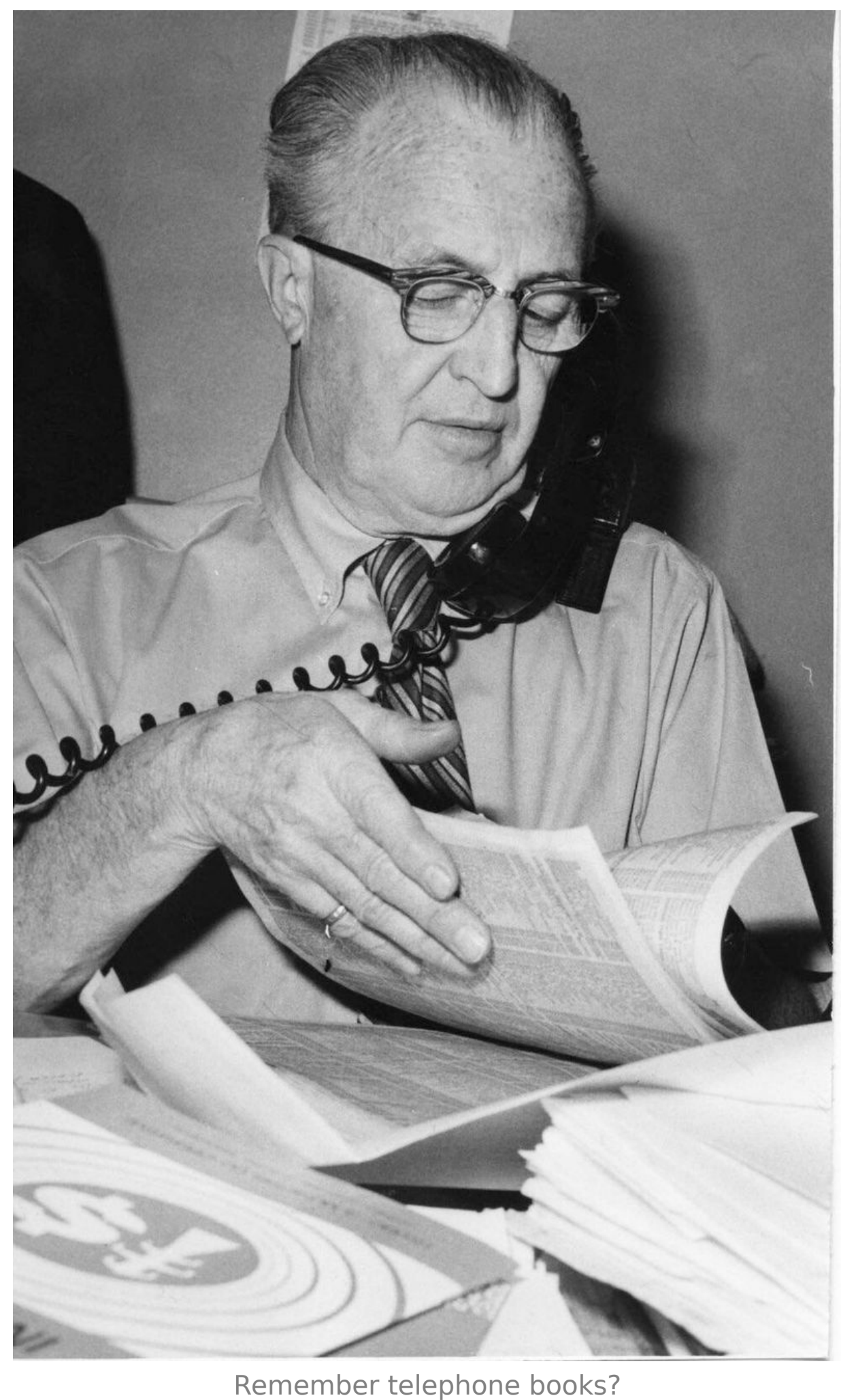


"[M]any people, especially those in positions of influence, strive to 'do things better,' which in practice amounts to 'do obsolete things better'"(Dindersmith 2018).

\section{Is My Learned Society Obsolete?}

This is just one question any open scientist hired on staff, or volunteering as a leader at a learned society needs to ask herself, and then others. In the last century and before that, learned societies flourished as homes for sub-disciplinary (and sub-subdisciplinary) journals and annual conversations. They also provide a lobbying voice for their segment of the science endeavor, which itself may be obsolescent. They offer a place for new scholars to meet established scholars, and they recognize and reward exemplary work.

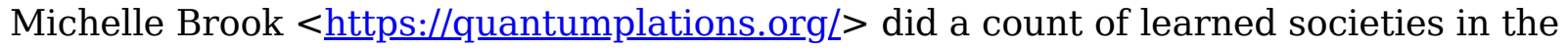
UK, and found more than eight-hundred of these. Across the globe there are thousands. One can imagine that each one of these does some good within its purview. The other side of this good, however, is the opportunity cost of their work (members might get more value elsewhere), and their relative ability to contribute to and benefit from open science. Your learned society may not have changed much for decades. Remember telephone books (and "telephones")? They were once essential. Now they are landfill. In the face of opportunities and change, all learned societies will need to find nimble footing going forward:

"[L]earned societies are part of the UK's knowledge economy and they can expect to see the pace of change and external competition increasing, so having a forward-thinking, adaptable and change-welcoming culture is important to their future survival" (Gardner 2013).

If your learned society is, in part, or on the main, obsolete, then making these obsolete bits better is the wrong way to spend your energies. Instead, you need to start the process of replacing obsolete practices, behaviors, and attitudes. This will be hard, but there are good resources here in the Handbook to help you out. So, what does obsolescence look like in the academy?

Note: there are lots of other (organizational, attitudinal, etc.) ways that your society may be obsolete. Here we will just list some of the ones that impact its role in open science.

\section{Seven obsolete features still found in learned societies:}


1. Journals/monographs that are based on the production of a paper product, and distributed through a subscription model.

The form of a paper journal creates an arbitrary scarcity to the publication. It's like you are publishing and privatizing the work of your members at the same time. University libraries are cajoled into subscriptions that must then be renewed for continuity (Also See: Learned Societies, Open Access, and Budgetary Cross-Subsidy $<$ https://eve.gd/2019/09/17/learned-societies-open-access-and-budgetary-crosssubsidy $/>$ Accessed September 17, 2019). Members are tasked to provide peer review. Most likely you already do a digital version, anyhow.

1. Step away from the cellulose and subscriptions and use the Internet. It's been around for decades. Your scientist readers around the globe will approve. Do you pay for what you do (outside of publishing/privatizing the journal) with moneys from subscriptions? First, you've been charging too much. Second, if what you do (scholarships, prizes, lobbying) is valuable to your members then charge them a membership fee. There are new business plan ideas that can help wean your society from its subscription addiction. Check out Harvard's Societies and Open Access

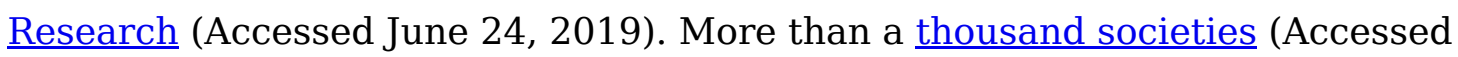
August 2, 2019) already have switched to open access. Add your name to this list! Suggested citation here: Society Open Access Research (SOAR) Catalog. Suber, Peter; Sutton, Caroline; and Page, Amanda. January 2019. http://bit.ly/oaj-society. CCBY-SA 4.0 International

2. Conferences with more than 300 participants.

This is not to say that you should not offer co-present events. If you are running a conference with a couple thousand members (or more, or many more), you are complexifying the central reason people have flown into your meeting: to find each other, and make new, or revive old, personal associations. Stepping into a big-city convention center with your colleagues may feel good, for about the first hour. After that it's all random noise.

Your conference carbon footprint is inexcusable. You should respect and support members who pledge to not fly at all (< https://www.theguardian.com/science/2019/jun/29/no-flights-four-day-week-climatescientists-home-save-planet> Accessed June 28, 2019)(See also: should climate scientists fly. Accessed June 24, 2019). Find creative ways to split up large 
national/international meetings into a number of smaller meetings with better focus and a lot more interpersonal time.

3. Poster sessions with no digital archive.

Posters are a good way to show off work in progress, and an opportunity for smallgroup interactions. They do take a significant amount of time to produce, so they deserve a permanent home on the internet. If the way you do your poster session is obsolete, you can fix that. Find an open online platform for poster sharing and use it well. And use better poster design requirements (Accessed June 24, 2019; video here) to help start conversations.

4. Meetings dominated by plenary talks and sessions devoted to individuals presenting papers.

Apart from a few plenary talks curated to help the room consider new technologies and findings that stimulate conversations, most talks can be recorded and posted online before the meeting, and not take up the agenda. Instead, do workshops and panels that provoke discussions and learning moments. Use conversation models (such as the world cafe) to bring together early and late career professionals. Long breaks, good food, nearby coffee houses, and beer also help.

5. No support for member collectives/clubs.

A mailing list is not a "community." You need to broadcast less and listen more. Your members need to find others working in very similar research arenas, and to have peerto-peer online collaboration tools. Help them do this. Become research match-makers and coordination masters. That's your new value proposition.

Are your association's membership numbers a metric for you? Is bigger really better? Remember that the r/science sub-reddit < https://www.reddit.com/r/science/> has twenty million members. Theirs is bigger than yours. Go online and build active communication/collaboration resources for your members.

6. No support for cross-disciplinary assemblages.

Real innovation happens when people bridge between disciplinary/domain-specific silos. The least your society can do is open up its digital holdings to be indexed broadly by others. The clubs that your society supports need to find clubs in other societies to share their issues and problems. You can seek out venues and avenues for conversations (online or in person) with other societies. No society is alone in this. 
7. Perhaps your whole learned society is obsolete. You may need to do a double loop rethink of its vision and purpose. perhaps at a board retreat somewhere, and rethink the entire purpose and vision for your society. If this society was created in a previous century to support a then-new sub-disciplinary journal, it may be a good time to pass this responsibility over to a pre-print repository and go home. Got some endowment money left over? Do a final meeting, make it free for graduate students and earlycareer folks, and challenge them to come up with the next best thing. Roll over the endowment to that. Got a big, fancy building for yourself? (Good for you!) Put it on the market, and use the funds to help all your employees find good jobs elsewhere.

"If you dislike change, you're going to dislike irrelevance even more" (Eric Shinseki < $\underline{\text { wikiquotes }}>$ Accessed 12/28/19).

\section{Don't stay obsolete, be leaders for the future of your domain}

Learned societies are well positioned to take leading roles in changing the behaviors of their members, though inclusive, member-led, reflexive culture change activities. They are often, however, keepers of a type of history that needs to be severed for them to move ahead. Their ceremonies and honors point to the past, to a graveyard of internally honored individuals (mostly white and male). They would do well to supplement their current honors with new ones that celebrate the future of their fields: early-career members, emerging sub-domains, collaboration successes, sharing and reuse.

\section{Bibliography: Open Scientist Handbook References}

